\title{
DISTRIBUTED BUSINESS INTELLIGENCE - A NEW APPROACH IN ECONOMICAL EDUCATION
}

\author{
Bănică Logica \\ University of Pitesti \\ Pitesti, Republicii street, 71 \\ Romania
}

\begin{abstract}
The focus area of this paper is twofold: covering the theoretical background about cloud-based Business Intelligence, and the practical approach using the Jaspersoft environment. Also, by choosing the main application area, we emphasized the advantage of using such instruments as an educational tool, with the goal of giving the students an opportunity to discover data collections and explore analysis methods.

After an overview of the Business Intelligence and Cloud Computing main concepts, we have pointed out the benefits of using BI in the Software as a Service (SaaS) philosophy, and we used the facilities of Jaspersoft BI software to model frequently used analysis requirements on several virtual firms.
\end{abstract}

\section{Keywords}

Business Intelligence, Cloud computing, Learning.

\section{JEL Classification Codes: 033, C81, D83 1. INTRODUCTION}

The goal of the paper is presenting the new cloud-powered Business Intelligence concept. We further present a series of theoretical and practical case studies that took place during the whole last year in the BI research field. Section 2 covers briefly the Business Intelligence (BI) and Cloud Computing (CC), with an accent on how they integrate.

The experimental part will focus on the role of BI tools in the management process of a company, with the Jaspersoft platform as a reference. Provided on Software as a Service basis, this approach offers many advantages: an increase in the cost-to-performance ratio, centralized management and professional security offered by the provider. The experiment covered the internship of 15 economic sciences students at the PRODINF Software Company and was supported by the SOP-HRD /109/2.1/G/81477 program of the EU.

The students were offered the chance to do remote practice, accessing the company's distributed infrastructure through the Internet in a secure manner. They used the ERP system developed by the company PRODINF Software to create and manage a set of virtual companies. We installed and ran Jaspersoft tools for all these companies and created reports, graphs and dashboards based on their financial data.

\section{THE CONCEPT OF CLOUD BUSINESS INTELLIGENCE}

This new concept results from the join of two technologies: cloud computing and business intelligence. Thus, we will briefly discuss to meaning of each component, how did the cooperation between them occur and which are the advantages of using Business Intelligence in the Cloud.

Also, we will present the different approaches of the concept:

\author{
Ştefan Cristian \\ University of Pitesti \\ Pitesti, Republicii street, 71, \\ Romania
}


- Infrastructure as a Service (IaaS) - the capability provided to the user to provision processing, storage, networks, and other fundamental computing resources (operating systems and applications).

- Platform as a Service (PaaS) - the capability provided to the user to deploy consumer-created or acquired applications onto the cloud infrastructure. The user does not control the cloud infrastructure (including the network, servers, operating systems, or storage), but has control over the deployed applications and possibly application hosting environment configurations.

- Software as a Service (SaaS) - provides a business application in the cloud; in this model cloud providers install and operate application software on their platform and users access the services remotely. The cloud users do not manage the cloud infrastructure on which their application is running. The application is not installed and does not run on client computers; in this manner the customer is not responsible for maintenance and support for the software.

Figure 1 presents the three fundamental models of cloud computing implementations.

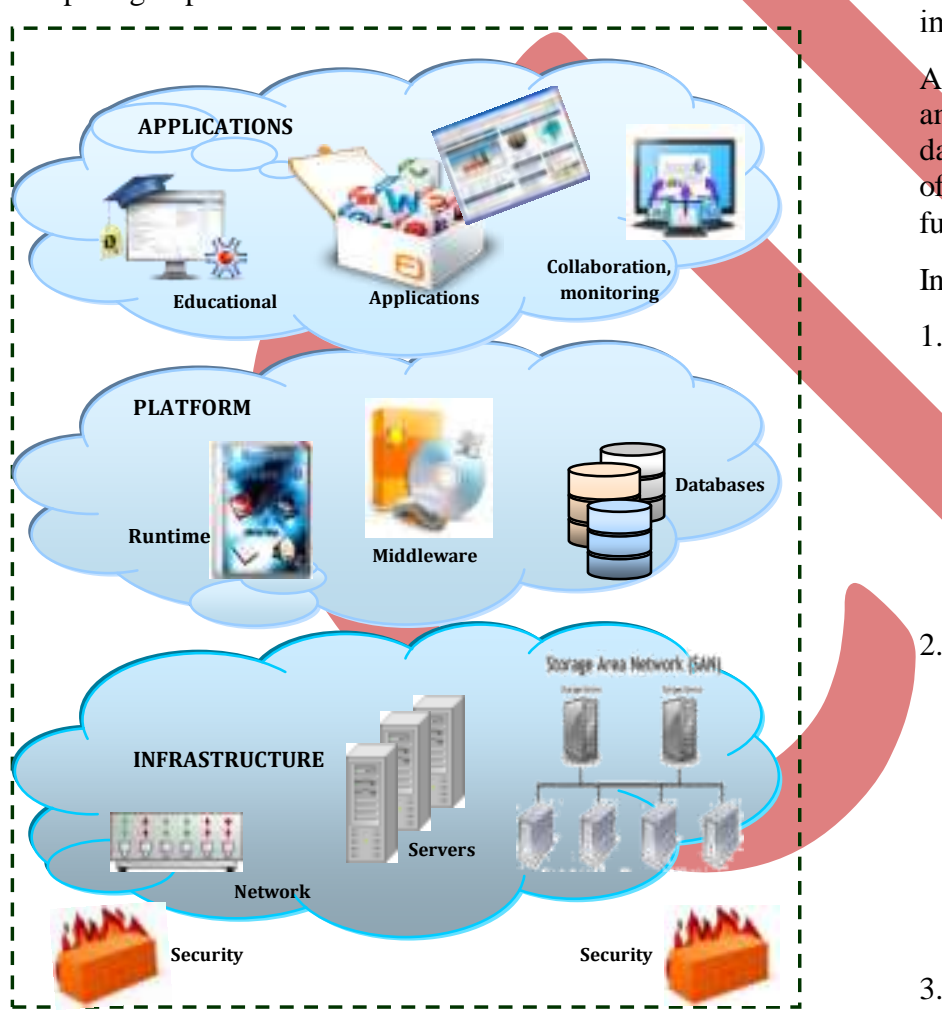

Fig 1: Cloud Computing Implementations

An implementation of computing clouds covers infrastructures of different sizes, with different levels of management, and different user numbers. We present several types, such as:

Public Cloud - the infrastructure is owned by a thirdparty organization providing cloud services and is available to the general public or large groups of users; their services are free or offered on a pay-per-use model.

Private Cloud - the infrastructure is owned, operated and managed by a private organization for its internal use only;
- Community Cloud - the infrastructure is shared by several organizations and supports a specific community that has similar approaches about policy, objectives, and security requirements.

Hybrid Cloud - the infrastructure is a joint solution of two or more clouds (private, community, or public) that are bound together by standardized rules that enable data and application portability.

\subsection{What is Business Intelligence?}

The paper is the result of a series of BI theoretical studies and practical experiments carried out by the authors throughout the year. We give a short presentation of the BI concept and its advantages for the companies who implement such software in their management processes.

Gartner's 2012 Research [6] defines a BI platform as software that delivers a range of capabilities organized into three categories of functionality: integration, information delivery and analysis. The second category is described as ,information delivery is the core focus of most BI projects today, but also there is an increased interest in deployments of analysis to discover new insights and in integration to implement those insights".

A BI system is built on a foundation consisting of large amounts of data, synthesized using new technologies such as data warehousing and data marts. The next step is the analysis of these data, finding patterns, relationships, structural, functional and causal types of connections.

In this manner, a BI system follows four stages [7][8]:

1. Obtaining the data - collects and organizes data from different internal and external sources; at this step a data warehousing solution is implemented that collects and organizes large data quantities from various sources. We consider this stage the most difficult because the derived model may not prove to be reliable enough, and thus it will be discarded with the reiteration of the whole process.

2. Analyzing the data obtained through $\mathrm{BI}$ operations - it is based on different types of management models for extraction, analysis, transformation and data processing; at this level reporting components (annual reports, analysis, dashboards, charts, etc.) are defined using technologies like OLAP (online analytical processing), data mining and analytical reporting, which offer the managers the ability to use data forecasting and "what-if" analysis.

3. Identifying trends, changes that occur and errors - this involves by data visualization tools, which can help to examine data graphically and to identify interrelationships; at this level, a very efficient solution can be to develop a business intelligence portal. The main purpose of a BI portal is to integrate data and information from a wide range of applications and repositories, in order to allow visualization of multiple systems, either internal or external to the organization, through a simple Web interface. Therefore, a BI portal can be seen like a Web-based, secure interface, which can offer a unique integration point for the applications and services used by employees, partners, suppliers and clients of the organization. The main advantage of the information portal is that it can be easily offered as a service based on a public or a private cloud. 
4. Simulations and gaining of new insights about business problems and opportunities; this stage provides the tools to gain more knowledge, to predict market evolutions based on data obtained from different business context.

We choose Jaspersoft as BI platform for our experiment, taking into account the study "Magic Quadrant for Business Intelligence Platforms" published by Gartner institute (research analysts: John Hagerty, Rita L. Sallam and James Richardson) in February 2012, after a detailed analysis of the strengths and weaknesses of most important BI software available on the IT market.

The following paragraph will summarize some of strengths and weaknesses of Jaspersoft BI software, according to the results of research studies in 2012 [6].

\section{A. Strengths}

First of all, Jaspersoft is an open-source BI platform;

Low price is the most compelling part of the Jaspersoft value proposition.

- Jaspersoft has the capacity to be embedded in the customer's software, without being bound by the GNU General Public License terms and conditions. The study remarks that Jaspersoft has more than 400 OEMs and SaaS (Software as a Service) providers that include Jaspersoft as the BI components in their software, offering the opportunity to integrate Jaspersoft into their internal applications. Jaspersoft also is partner into an important IT network that includes companies such as Red Hat, VMware, IBM and Tata.

- The compatibility with cloud deployments.

- To help both faculty and students assess for themselves the value of open source software solutions, Jaspersoft has provided a suite of BI solutions in educational purpose.

B. Weaknesses

Gartner analysis emphasizes that Jaspersoft is implemented in smaller companies with smaller volumes of data than the survey average, having as field of application departments rather than enterprises.

- Generally, Jaspersoft customers use BI platform for reporting, even if the software has a complex set of functions available. This weakness is consistent with Jaspersoft's origin as an open-source reporting tool; the customers have not yet begun implementing the entire set of BI functionality available as part of the Japsersoft BI platform.

- Jaspersoft score was almost the lowest for the second year in a row, despite this being a key part of the company's business models.

Jaspersoft has an average score based on few criteria: ease of use for both, end users and developers, the integration of its BI platform components, its product quality and its performance.

Jaspersoft has integrated support for cloud services, and the migration of data processing from the desktop to the highlyavailable, easy scalable virtualized environments has established as a constant industry trend in the last years.

\subsection{Meeting Business Intelligence with Cloud Computing}

Various application migration (in this case, Business Intelligence software) to cloud computing is the most difficult aspect because there are some rules and principles that should be adopted in this shared environment. For this purpose, more providers such as Jaspersoft, Talend, RightScale, and Vertica have teamed up to offer a joint solutions package that delivers Business Intelligence (BI) in the cloud, according to research firm Gartner [6].

JasperSoft Inc. has a powerful strategy to cooperate with companies that host public or private clouds. For example, open source BI pioneer JasperSoft Inc. recently announced a new partnership with VMware Inc. to deliver platform-as-aservice (PaaS) BI and also a similar accord with Red Hat, while having an existing arrangement with Amazon for SaaS type BI.

A key aspect of JasperSoft's partnerships with both Red Hat and VMware concerns embedded BI, or BI in the context of PaaS. There are many requests from Jaspersoft-interested developers to move to the cloud.

Cloud computing is the technology that many small and medium companies have chosen, and it has a powerful impact on the business intelligence industry also.

It is a simple logic behind that action: by its definition, BI helps companies analyze data and answer with valuable business information. As more and more data and applications migrate to the cloud, new data sources are being created and BI users can use this opportunity and integrate their tools into this new environment.

Being a newly introduced paradigm, both pro and con discussions about deploying cloud-based BI solutions exist, as follows [9][10]:

\section{a) Advantages}

- Scalability - the main feature of cloud-based services is that they are incredibly flexible in adapting to the size of the client, and thus even small-scale companies can benefit from BI insights.

Simplified deployment - the company does not have to support the high expenses for maintaining a complex IT infrastructure anymore, as the solution runs in the datacenter of the cloud hosted.

- Cost - there is the option to lease the service and use a pay-as-you-grow model, avoiding the elevated costs implied by acquiring a site license from the beginning.

b) Drawbacks

- Security - all the hassles of securing the data and running the system without downtimes are assumed by the service provider, and handled by their skilled professionals. The BI user should trust and rely on them to do a good work.

- Emerging Technology - all the unknown bugs and hidden problems that this new approach still hides are to be managed by the company that runs the cloud platform, and may imply business interruption for the customer that uses BI applications.

- Data Movement - all data that the company with BI requirements has to process will be hosted by a third 
party, and their confidentiality should be guaranteed by a strong non-disclosure agreement.

\section{EXPERIMENTAL BI APPLICATION DEPLOYED AS SAAS}

This section will describe an experiment representing the experience of a group of students with databases, accountancy, and operating systems background; each one of them was asked to develop and manage a virtual company in a cloud environment for a problem of interest in their research area.

The IT company PRODINF Software decided to offer the students free access to a private cloud dedicated to higher education and to deploy its own application EMSYS - an enterprise resource planning software system.

Which one of the two cloud computing paradigms, SaaS or PaaS is better?

The study involved the internship of 15 students, and was partially funded by the SOP-HRD program "A self-potential increase for the economical science students in order to help them to integrate the labor market".

The students have had a virtual practice stage as they could access the hardware and software resources offered by Prodinf from any place with an Internet connection, and thus reducing the need to travel. They have built virtual firms within the EMSYS platform and loaded the data required to simulate their operation in a competing market environment. We have analyzed a few such simulations from the point of view of the $\mathrm{BI}$ interested manager, and fulfilled all steps required for BI modeling with the Jaspersoft tools.

The experiment is at the beginning and it started during the practice stage (3 weeks, 6 hours each day) in two undergraduate classes of our Departments: Computer-aided accountancy (CAA) and Business administration (BA) from the Faculty of Economics, University of Pitesti, Romania.

Practically, we simulated a virtual students' practice vs. a traditional one and we tried to prove the advantages of this new method:

- The internship does not involve any extra-spaces;

- Individual study and practical work takes place after the classes;

- The study began on a demo-company;

- Each student has its own company for practice;

- All practical works are mandatory for the student;

- Availability: 24 hours weekly.

The internship for the students was ended by a project that involved the stages presented above for each virtual company that they had to manage [13].

Virtual practice offers the students a possibility to work on the university network or on their personal computers. Students already have basic knowledge of database design and implementation from previous years of study, prerequisites for building a data warehouse for small and medium business. Well-known DBMSs supported by Jaspersoft include PostgreSQL, Oracle, IBM DB2, Microsoft SQL Server and MySQL - all of them compliant with JDBC (Java Database Connectivity) technology, as Jaspersoft is a J2EE-based server application. It can use any open-source (Tomcat) or commercial application server (JBoss, WebLogic, WebSphere).

Jaspersoft has integrated support for cloud services, and the migration of data processing from the desktop to the highlyavailable, easy scalable virtualized environments has established as a constant industry trend in the last years.

This section shortly explains how to prepare the data to be used in reports, OLAP views, and dashboards in Jaspersoft. A sample data source is organized in a data structure, using the fields (attributes) to define relationships between tables. We propose the following structure of an Access database, designated to store financial results for the example company presented (figure 2).

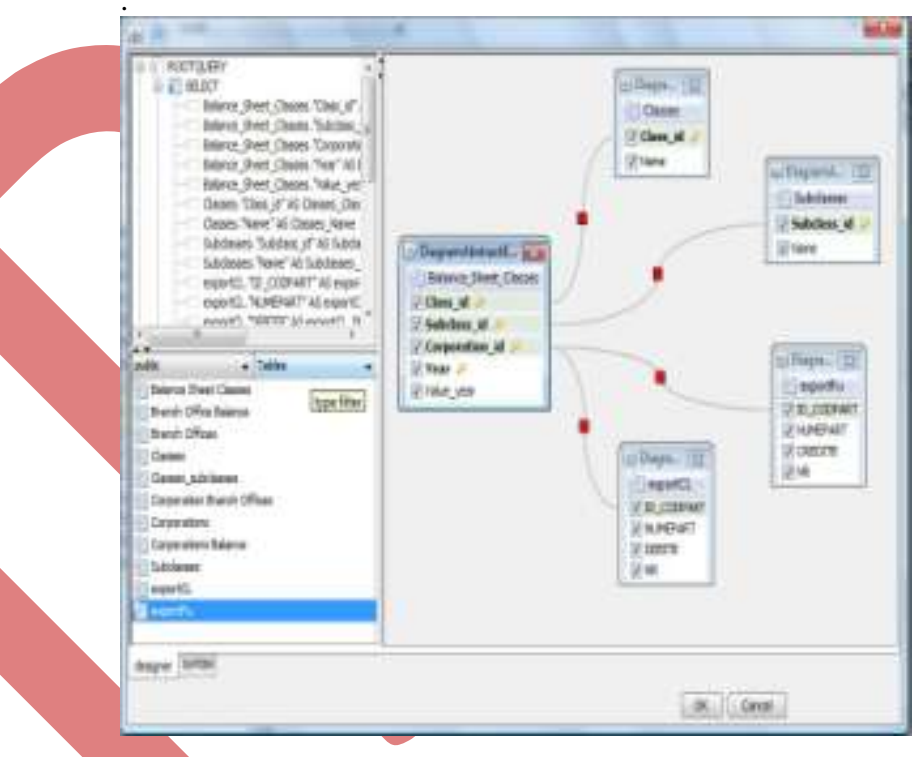

Fig 2: Tables and relationships

There are many free software tools to accomplish the migration from any type of database into a PostgreSQL database, default for Jaspersoft. An example is the Navicat for PostgreSQL, having also a trial version (figure 3.). Then, students must define a data source connection inside Jaspersoft. To connect to a data source it is important to configure the Data source and define a driver by setting the server path and database name in the JDBC Wizard. 


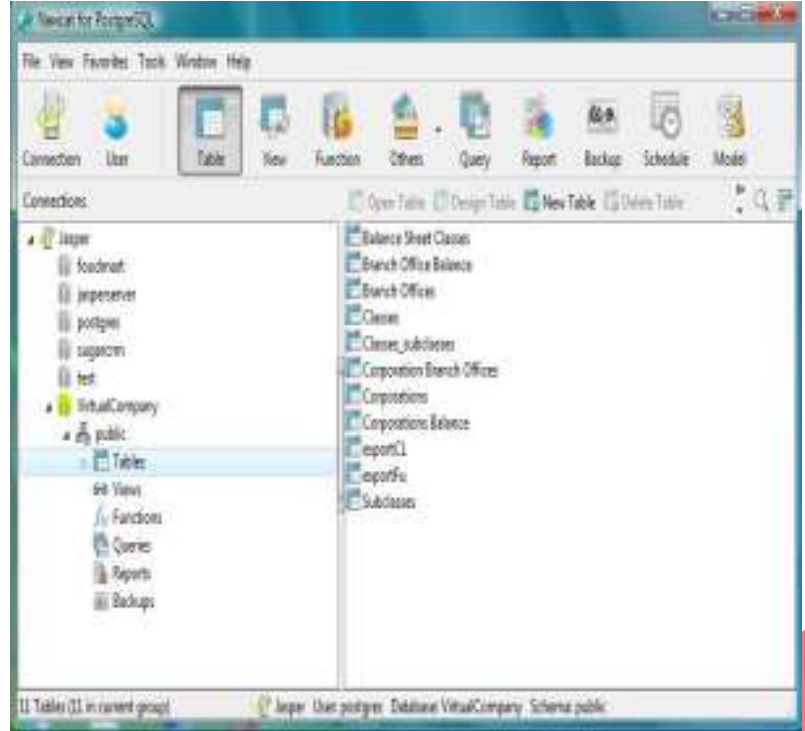

Fig 3: Migration of student databases to PostgreSQL environment

Before using BI application, users must analyze the information they need to collect, in order to facilitate decision-making, as well as the form in which information should be presented to different hierarchical levels of the management- such as generating reports, providing processing and comparative data, analysis of different trends, influences, costing, determining the profit variable [11].

After this mandatory analysis, students will be able to properly use the Jaspersoft software. The first operation define domains to join, next they will define a filter and will realize the processing of the data using either the Ad Hoc Editor or Jasper iReport Designer - figure 4.

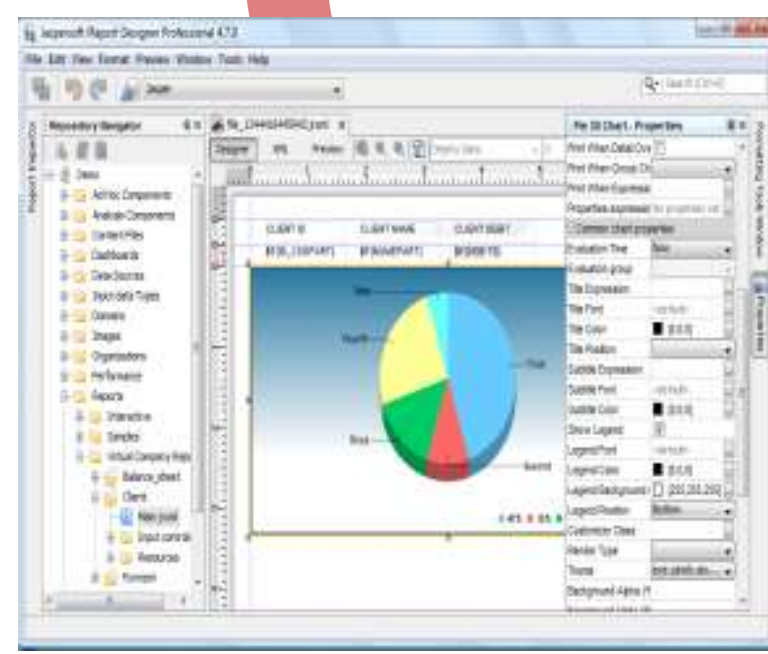

Fig 4: Using Jaspersoft iReport Designer for projecting reports, charts

Business Intelligence can potentially influence the core of a firm's activities such as choices pertaining to products, markets, and technologies (the corporate strategy level), as well as competitive methods within each of the productmarket segments (the business strategy level) [12].

We focused in this paper on the first level, which consists of learning how to execute routine tasks of an organization. Students must define the Domain, which is a virtual view, created and stored on the server without modifying the data source. Through a Domain, users see columns that have been joined, filtered and labeled for their business needs; also they may create reports using iReport. Users can save a report based on a Domain for others to run, and can also save the settings in a Domain Topic so others can design similar reports.

Based on a domain, the students learn to create Reports, using iReport Designer by dragging and dropping columns of data onto a table, chart, or crosstab. Users may create dashboards interactively in the Dashboard Designer and save them in the repository. A Dashboard is a collection of reports, input controls, graphics, labels, and web content displayed together. In figure 5, a dashboard presents a comparative analysis of two virtual firms, opposing the financial results of the chosen companies.

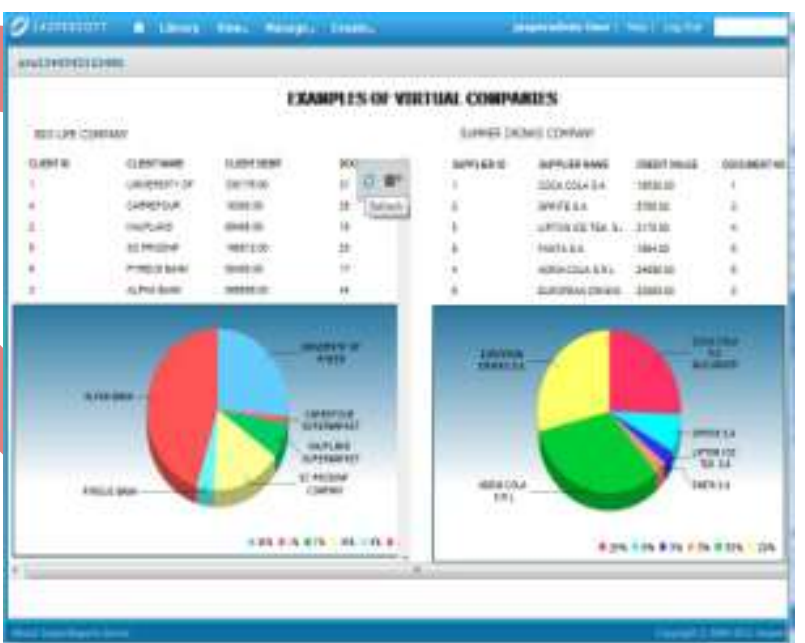

Fig 5: A comparative analysis of the financial results of two virtual companies

\section{CONCLUSIONS}

The paper emphasizes the two main highlights for the future of the business environment that cloud-powered BI integration can offer:

- the advantage for the companies, in deep market knowledge, ease of management and financial optimizations;

- help the students to prepare themselves for the future activities required at their workplaces.

Such an infrastructure is able to extend as necessary, based on user requirements, and is able to host a great number of students for long periods of time, as flexible storage capacity and communication channels are already built-in by the vendors.

This approach will allow the young economists to develop their skills and exchange ideas, learn from each other and build a strong foundation for real-world applications that will follow after graduation. Also, teamwork and hands-on experimentation without the risk of involving real money can improve their abilities to make decisions and assess their efficiency before their position in a company will require it. The global economy is a highly interconnected environment and a simulation could involve not just individual companies managed by each student, but also working in departments for a multi-national virtual enterprise, in order to accommodate with the requirements of such a challenge. This way, every student is a part of a great team, with common goals and 
Council for Innovative Research www.cirworld.com
International Journal of Computers \& Technology

Volume 3 No. 3, Nov-Dec, 2012 deadlines. Each decision has an impact on all the others, and communication becomes essential.

\section{ACKNOWLEDGMENTS}

The authors wish to thank the SOP-HRD programme of the EU for the partial funding of this research, based on 109/2.1/G/81477 grant.

The work of Cristian Stefan was supported by grant $88 / 1.5 / \mathrm{S} / 52826$.

\section{REFERENCES}

[1] Mell, P. and Grance, T. "NIST Definition of Cloud Computing V15." http://csrc.nist.gov/groups/SNS/cloudcomputing/index.ht $\mathrm{ml}$

[2] C. Cacciari, F. D’Andria, M. Gonzalo, B. Hagemeier, D Mallmann, J. Martrat, D. G. Perez, a. Rumpl, W. Ziegler, and C. Zsigri. "elasticLM: A novel approach for software licensing in distributed computing infrastructures.", Proc. IEEE 2nd Int. Conf. on Cloud Computing Technology and Science, pp. 67-74, 2010.

[3] Gray, M. "Cloud Computing: Demystifying IaaS, PaaS and SaaS.", http://www.zdnet.com/news/cloudcomputingdemystifying-iaas-paas-and-saas/477238, 2010.

[4] M. O’Neill. "SaaS, PaaS, and IaaS: A security checklist for cloud models." http://www.csoonline.com/article/660065/saas-paas-andiaas-a-securitychecklist-for-cloud-models, 2011

[5] Williams, A., "The Feds, not Forrester, Are Developing Better Definitions for Cloud Computing." http://www.readwriteweb.com/enterprise/2009/10/forrres ter-says-we-need-better.php, 2009.
[6] Hagerty, J., Sallam, R., L., Richardson, R., Magic Quadrant for Business Intelligence Platforms http://businessintelligence.info/docs/estudios/MagicQuadrant-for-Business-Intelligence-Platforms-2012., 2012.

[7] Kocbek, A., Juric, B.M., „Using advanced Business Intelligence methods in business process management", Conference on Data Mining and Data Warehouses (SiKDD 2010 ), Ljubljana, Slovenia, 2010

[8] Bara, A., Botha, I., Diaconiţa, V., Lungu, I. et al, A model for Business Intelligence Systems' Development, Informatica Economică, Vol. 13, No. 4, pp 99-108, 2009.

[9] Bharat Chadha, Meena Iyer, „BI in a Cloud: Defining the Architecture for Quick Wins”, SETLabs Briefing, Vol 8, No.1, pp39-44, 2010

[10] Chris Hagans, "Business Intelligence in the Cloud", http://cloudcomputingtopics.com/2011/09/businessintelligence-in-the-cloud/, 2011

[11] Aara, S., A., Qasim, Z., Muralidharan, P., Merging Organizational Management and Information Technology through Business Intelligence, Proceedings International Conference on Technology and Business Management, pp.930 - 35, Dubai, United Arab Emirates, 2011

[12] Gile, K., „The Forrester Wave: BI Reporting and Analysis Platforms", 2006, http://www.Jaspersoft.com/resourees/whitepapers

[13] Christopher W. Taylor, „A Study of Student use of Cloud Computing Applications", Journal of Information Technology Management, ISSN \#1042-1319, Volume XXII, Number 3, pp.36-50, 2011 